\title{
25 Research Soure \\ Exploring Medical Response Preparation Strategies for Terrorist Subway Dirty Bomb Explosion Based on A Simulation System
}

\section{Tiecheng Yan}

Center for Disease Control and Prevention of Northern Theater Command https://orcid.org/0000-00029393-638X

\section{Yuxuan Yang}

Academy of Military Medical Sciences

Min Yu ( $\square$ yumin_20212021@163.com)

Academy of Military Medical Sciences https://orcid.org/0000-0002-6979-8001

\section{Research}

Keywords: Dirty bomb, Simulation, Subway, Terrorism, Medical response

Posted Date: August 23rd, 2021

DOI: https://doi.org/10.21203/rs.3.rs-820788/v1

License: (c) (1) This work is licensed under a Creative Commons Attribution 4.0 International License. Read Full License 


\section{Abstract}

Introduction: London bombings on July 7, 2005 presented serious difficulties for medical response, moreover, if a dirty bomb attack had occurred in an underground train, it would have been more difficulties to cope with. Based on this possibility, it is critical to take strategies on medical response to dirty bomb attacks in underground transport systems into account beforehand.

Method: In the Windows 10 operating system, visual studio 2019 environment, we used C ++ language to develop a system that can simulate the process of nuclear or radiological emergency medical rescue based on discrete event simulation, mainly considering the designs of professional rescue groups, staffs' energy consumption, injured and uninjured persons on site, and competence value of key staffs.

Results: In the scenario of a subway dirty bomb terrorist attack causing 2.6 casualties per minute and 208 casualties in total, the manpower needed for the emergency medical response were 5 pre-triage groups, 7 contamination triage groups, 23 decontamination groups, 5 first-aid groups, and 12 comprehensive treatment groups. Besides, 5 first-aid groups and 45 decontamination groups were added to implement on-site rescue. The total number of actual participants in the medical response should be about 337. More than 337 PPE should be prepared.

Conclusion: We designed and constructed a simulation system, and used it to explore the medical response preparation strategies for subway terrorist dirty bomb explosion, including preparation of sufficient staffs and equipment, consideration of the rotation needs of the staffs, and perception of realtime situation on site and agile command, especially obtained the prediction method of staff and equipment resources for specific disaster background, which could provide constructive references for the security protection of urban subway systems in the future.

\section{Introduction}

On 7 July 2005, four suicide bomb attacks took place in London - three in London Underground trains and one on a double-decker bus, which killed 56 people and injured more than 700 individuals ${ }^{[1]}$. Before the attacks happened, all the emergency services in London had prepared extensively for such attacks, however, the attacks still presented difficulties as the scale of attacks was unprecedented and the underground locations were restricted for site access ${ }^{[2]}$. If a dirty bomb attack had occurred in the underground train, it would have been more difficulties to cope with. A dirty bomb is made of radioactive materials mixed with explosives. The explosion could have a similar lethality to that of an ordinary bomb and produce radioactive pollutants that have ionizing radiation effect on the human body, which increases the complexity of the medical response. Based on this possibility, it is necessary to come up with strategies of medical response to dirty bomb attacks in underground transport systems beforehand, such as preparation of adequate medical and paramedical staff and equipment, on-site response command planning, which can provide references for dealing with the extreme threat of terrorism, and promote the capability of the medical response to such attacks. 
Radioactive materials are used every day in laboratories, medical centers, food irradiation plants, and for industrial uses. If stolen or otherwise acquired, many of these materials could be used in a "radiological dispersal device" (RDD), like dirty bombs, so a lot of researches have been done on medical response to this very possible kind of terrorist attack. Current researches are mainly about several aspects, including risk factors of dirty bomb attack ${ }^{[3]}$, evaluation of the medical response capability ${ }^{[4]}$, technology ${ }^{[5-7]}$, and strategy of the medical response ${ }^{[8-17]}$. Current strategy researches mainly focused on analysis and selection of response strategies, a few studies emphasized the legal issues ${ }^{[16]}$ and the cognitive attitude of medical staff on response strategies ${ }^{[13]}$. The research methods include drill, literature review, focus group interview, Haddon matrix, Bayesian model, and simulation. In the current research, there is still a lack of specific staff and equipment preparation research for mass casualty dirty bomb attacks. Through this research, we can prepare and execute a more precise plan for such emergencies, and implement accurate response preparation work, which can promote the efficiency of the emergency response.

Since it's impractical to organize a drill under mass casualty incident $(\mathrm{MCl})$ background, we constructed a discrete event simulation system to analyze the medical response process based on a serious subway dirty bomb attack scenario. The response strategies were proposed mainly in preparation of skilled onsite medical staff and equipment.

\section{Methods}

In the Windows 10 operating system, visual studio 2019 environment, we used C ++ language to develop a system that can simulate the medical rescue process of nuclear or radiological emergency based on discrete event simulation. This section describes the process and the main design features of the system.

\subsection{Nuclear or Radiological Emergency Medical Rescue Process}

Below is the detailed medical rescue process including stages of triage, decontamination, and prehospital care.

A victim undergoes up to several steps of process at the emergency site as illustrated in Fig. 1. The pretriage is performed normally by a team of one physician and two medics who classify victims into five groups: Uninjured (may be contaminated), slightly injured, badly injured, seriously injured, extremely injured. Persons seriously injured and extremely injured are sent to pre-hospital treatment immediately, then decided to receive decontamination or transportation to hospital based on their health status, persons extremely injured are treated with lower priority due to their low chance of survival. Persons of other three groups are sent to contamination triage, then decided to receive decontamination or comprehensive treatment (non-urgent medical care, include psychological stress intervention) based on their contamination status, all these persons need comprehensive treatment finally.

\subsection{Features of the system}

\subsubsection{Design of professional rescue groups}


Each professional group is designed as the basic unit in the simulation, the composition of all kinds of group members in the unit is not displayed. Each ambulance or helicopter is an evacuation unit. The maximum number of slightly or seriously injured persons carried by ambulance and helicopter can be set by researchers according to the objective situation. The number of all types of rescue groups can be adjusted freely.

Based on uniform distribution, the rescue time length of each group to each person is randomly allocated with a time range in minutes, and the upper and lower limits of the range can be set according to the objective situation.

\subsubsection{Design of staffs' energy consumption}

We set the energy value of a staff $0-100$, as the rescue going on, the value gradually decreases from 100 , when the value drops to 0 , that staff will be required to stop, and retreat. The rescue will restart at the point that new staffs rotate. Staffs' energy consumption rules are as follows.

The energy value is $100-a t_{1}-b t_{2}$, where $T_{1}$ is the duration for the medic to wait for the injured person at work post, $T_{2}$ is the rescue duration, $a$ is the energy attenuation coefficient during the waiting duration, and $b$ is the attenuation coefficient during the rescue. $A=100 /$ the duration that the medic can keep waiting for injured person in the designated post $(\min ), B=100 /$ the duration that the medic can keep implementing the rescue in the designated post $(\mathrm{min})$. The attenuation coefficient is different in various posts, and set according to the previous training experience.

\subsubsection{Design of injured and uninjured persons on site}

The number of the injured person can be assigned by the researchers according to the incident scenario, the minimum number is 1 , with no upper limit, following the objective situation of nuclear or radiological emergencies.

The proportion of injured levels (uninjured, slightly injured, badly injured, seriously injured, extremely injured), the proportion of persons contaminated and uncontaminated, and the percentage of injured persons in comprehensive treatment unit who need to be evacuated can be assigned in incident background.

The generation of the casualties is a random process described by Poisson distribution. The time interval of casualties arriving at the triage point is in negative exponential distribution.

In accordance with Rauner M. S.' research [18], the health values range between 1 and 100, with a value of $<1$ representing 'dead', and 100 as uninjured. Each injured person is assigned an initial health status based on the different injured situation, the analysis utilizes uniform distributions with values ranging from $1-10$ for extremely injured persons, $11-40$ for seriously injured persons, $41-65$ for badly injured persons and $66-99$ for slightly injured persons. A person with a health value less than or equal to 40 will 
be assigned into first-aid group, and a person with a health value over 40 will be assigned into contamination triage group.

The wait for treatment might deteriorate the health status of an injured person. This concept is only used for heavily injured persons(those assigned $1-40$ points), because they may die after a certain time due to heavy conditions such as bleeding or respiration problems without timely treatment, the health value decreases with the increase of wait time. The maximum waiting time for treatment is assumed to follow a uniform distribution with a minimum value between $5-80 \mathrm{~min}$ and a maximum value between $80-280 \mathrm{~min}$.

The health status of injured persons may be better after treatment. The promotion range of health value follows a uniform distribution, with a minimum value between $-10-0$ and a maximum value between $5-35 \mathrm{~min}$. The health status of injured persons with $1-10$ may change in a range between $-10-5$ randomly. Starting from the health value 11 , the change of health value increases gradually. For the heavily injured persons with a health value under 20 , the minimum value of the change rises to 0 and the maximum value rises to 15 . For the injured persons with health value $21-40$, the minimum value of the change is kept at 0 , and the maximum value will not increase after it rises to 35 , which means the maximum value of health status promotion is 35 for a 40 point injured person.

\subsubsection{Design of competence value of key staffs}

The competence value ranges from 60 to 99 points and is divided into four grades ( $90-99,80-89$, $70-79$ and $60-69$ points). The lower the competence grade, the less efficient the rescue will be.

For the pre-triage group, the efficiency is reflected in the accuracy of pre-triage. The lower the competence grade of the pre-triage group members, the more likely it is to triage the badly injured person as the heavily injured person, which will increase the burden of the first-aid group, or triage the heavily injured person as a badly injured person, which will delay the treatment.

The overtriage rate is defined to capture the proportion of unnecessary use of hospital resources on minor trauma(resource overutilization) ${ }^{[19]}$. Out of the four explosion sites in the 2005 London bombings, the minimum rate was $27 \%$, the maximum rate was $88 \%$, and the total overtriage rate was $64 \%{ }^{[1]}$. The undertriage rate is often defined to capture the proportion of major trauma receiving suboptimal care, increasing the risk of mortality or adverse outcomes, the mean undertriage rate was $0.05 \%$ reported by previous literature $^{[20]}$. In our research, the first competence grade of the pre-triage group is with an overtriage rate of $20 \%$ and below and 0 undertriage rate, the second competence grade is with $21-40 \%$ overtriage rate and $0-0.03 \%$ (not 0 ) undertriage rate, the third competence grade is with $41-60 \%$ overtriage rate and $0.04-0.06 \%$ undertriage rate, the fourth competence grade is with $61-80 \%$ overtriage rate and $0.07-0.1 \%$ undertriage rate.

For the decontamination group, the rescue efficiency is embodied in decreasing the duration of injured person decontamination. The lower the competence grade of the decontamination group members is, the 
more time is needed for decontamination. The decontamination duration of the first competence grade remains unchanged, the second, third, fourth competence grade indicates the duration is increased by $10 \%, 20 \%, 30 \%$ separately.

For the first-aid group, the rescue efficiency is reflected in the increase of the health value. The lower the competence grade of physicians in the first-aid group is, the more limited the increase of the heavily injured person's health value after treatment is. The health value increase of the first competence grade remains unchanged, the second, third, fourth competence grade indicates the health value is $90 \%$, $75 \%, 65 \%$ of the value increase of the first competence grade.

\subsubsection{Design of statistical indexes}

The main statistical indexes of simulation analysis include average waiting time in queue, the number of each group participating in the rescue, the number of deaths, and the duration of rescue(from the first casualty pre-triage to the last casualty evacuation).

\section{Results}

Due to the lack of data of mass casualty incident of nuclear emergency medical response, and with the research background of dirty bomb terrorist attacks in the urban subway system, the data of London bombings on July 7,2005 , was used as the basis of simulating the casualty flow.

According to the report, the nearest hospital to the explosion site of Aldgate subway station received 208 casualties $^{[21]}$, and the rescue staffs transferred all the casualties for about 1 hour and 20 minutes ${ }^{[22]}$, that means the hospital received an average of 2.6 casualties per minute with the above data. In the four explosion sites of the London terrorist attack, the casualties at Aldgate subway station were transferred fastest. To analyze the preparation for the relatively serious situation, we selected 2.6 casualties $/ \mathrm{h}$ as the flow rate in the simulation, and 208 as the total number of the casualties. The energy consumption coefficients and the rescue operation duration of each group are set based on the training and drill, the competence value of key staffs is set as the highest grade, the extremely injured person can wait for treatment for $5-80 \mathrm{~min}$, the seriously injured person can wait for treatment for $80-280 \mathrm{~min}$, the extremely injured person's health value changes in range - $10-5$, the seriously injured person's health value changes in range $0-15$, and the health life value of an injured person in comprehensive treatment group changes in range $3-15$. As the report of London bombings ${ }^{[1]}, 52.8 \%$ of the victims were slightly injured, $39.6 \%$ were badly injured, $4.8 \%$ were seriously injured and $2.8 \%$ were extremely injured.

It was required that the injured persons should wait for the shortest length of time in the first-aid group and the pre-triage group, and the average waiting time of other kinds of groups should not exceed half a minute. After 30 times simulation operations, the following rescue group disposition was obtained: 5 pretriage groups, 7 contamination triage groups, 23 decontamination groups, 5 first-aid groups, and 12 comprehensive treatment groups. The simulation index results are as follows (Table 1): 
Table 1 Simulation Index Results

\begin{tabular}{lll} 
Index & Median & Range \\
\hline ·Duration of rescue & $96 \mathrm{~min}$ & $95 \sim 97 \mathrm{~min}$ \\
\hline ·Average waiting time in the pre-triage stage & $0.11 \mathrm{~min}$ & $0.05 \sim 0.24 \mathrm{~min}$ \\
\hline ·Average waiting time in the contamination triage stage & $0.25 \mathrm{~min}$ & $0.1 \sim 0.67 \mathrm{~min}$ \\
\hline ·Average waiting time in the decontamination stage & $0.15 \mathrm{~min}$ & $0.02 \sim 0.71 \mathrm{~min}$ \\
\hline ·Average waiting time in the comprehensive treatment stage & $0.3 \mathrm{~min}$ & $0.06 \sim 0.99 \mathrm{~min}$ \\
\hline -Average waiting time in the first-aid stage & $0.01 \mathrm{~min}$ & $0.01 \sim 2.21 \mathrm{~min}$ \\
\hline -Number of vehicles for evacuation & 15 & $14 \sim 17$ \\
\hline ·Number of first-aid groups added & 5 & $2 \sim 5$ \\
\hline -Number of decontamination groups added & 45 & $39 \sim 46$
\end{tabular}

The simulation results show that the rescue duration was 96 minutes, and it took 80 minutes for all the victims to be transferred out of Aldgate underground station(enter the medical rescue process at the same time), and more than ten minutes for the last victim to go through the rescue process, so it was objective and reasonable that the rescue duration was 96 minutes.

five first-aid groups and 45 decontamination groups were added to implement on-site rescue, which indicated that the first-aid group members were rotated once due to lack of energy, and the decontamination group members were rotated twice, that is consistent with the objective situation of nuclear or radiological emergency medical rescue training and drill. In hot summer, it is difficult for decontamination and first-aid group members with personal protection equipment (PPE) to maintain continuous rescue operation for more than one hour in the confined space. The above analysis proves the validity of the simulation simultaneously.

\section{Discussion}

The manpower and equipment resources needed to implement the rescue can be estimated by the number of groups and the rotation times obtained from the simulation experiment.

For the implementation of emergency medical response to a subway dirty bomb terrorist attack with 2.6 casualties per minute and 208 casualties in total, the manpower needed for each group are shown in Table 2:

Table 2 (Part of) demanded manpower of the simulated medical response process 


\begin{tabular}{llll} 
Group & $\begin{array}{l}\text { Number of staffs per } \\
\text { group }\end{array}$ & $\begin{array}{l}\text { Number of groups } \\
\text { required }\end{array}$ & $\begin{array}{l}\text { Total number of } \\
\text { staffs }\end{array}$ \\
\hline Pre-triage & 2 & 5 & 10 \\
\hline Contamination triage & 2 & 7 & 14 \\
\hline Decontamination & 3 & 23 & 69 \\
\hline $\begin{array}{l}\text { Comprehensive } \\
\text { treatment }\end{array}$ & 2 & 12 & 24 \\
\hline First-aid & 2 & 5 & 10 \\
\hline Evacuation & 3 & 15 & 45
\end{tabular}

According to the above table, a total of 172 staffs are required to carry out medical response at the same time. However, the number of staffs should far exceed 172, because the commander, the risk reconnaissance staff, the logistic service staff, and the rotation staff have not been taken into consideration. Only the decontamination and first-aid groups have to be rotated, so the number of the two group staffs have an increase of $145(3 \times 45+2 \times 5)$. We assume that the total number of the commander, risk reconnaissance staff, and logistic service staff is 20 . Consequently, the number of staffs actual participating in the medical response should be about $337(172+145+20)$.

PPE and professional rescue equipment of each group are the main considerations of resources. The rotation needs to be considered in the preparation of PPE, as a result, the basic number of PPE is also 337. However, more than 337 PPE should be prepared in case of accidental damage. The professional rescue equipment needs to be prepared according to the number of groups required which has been worked out by the simulation.

The analysis above indicates that a great deal of manpower and equipment resources are needed for the implementation of emergency medical response to such an $\mathrm{MCl}$ caused by a terrorist attack in the underground system, which is a big challenge for any city.

The strategies are summarized as follows:

Preparation of sufficient staff and equipment This research estimated that the implementation of emergency medical response to such a dirty bomb attack needs about 337 professionals, more than 337 sets of PPE, and 70 sets of equipment of various groups. However, considering the severity of an incident, the preparation can be enhanced or reduced on this basis.

Consideration of the rotation needs of staffs Compared with the rescue without toxic factors, more energy of the staffs would be spent in nuclear or radiological emergency medical response, because PPE accelerates the energy consumption, especially in hot summer. The rotation of group members is the objective demand that must be considered. 
Perception of the real-time situation on-site and agile command It is a complex command process to carry out emergency medical response to $\mathrm{MCl}$ caused by subway dirty bomb terrorist attack. The deposition of the response resources in advance is difficult to fully match the needs of rapid and effective rescue because the time and place of the incident onset are unpredictable. Therefore, it is necessary to establish and improve the information communication mechanism and quickly respond to the incident with the help of a relevant intelligent command system. Real-time situation perception and agile command are the guarantees of efficient emergency medical response implementation.

\section{Conclusion}

In this research, we designed and constructed a simulation system, and used it to explore the medical response preparation strategies for subway terrorist dirty bomb explosion, especially obtained the prediction method of staff and equipment resources for specific disaster background, which could provide useful references for the security protection of urban subway systems in the future. The simulation system focuses on our concept for the organization of nuclear or radiological $\mathrm{MCl}$ response, but this could be expanded to other fields or countries and surely improve planning and scheduling of $\mathrm{MCl}$ in case of urgent demand. However, due to no dirty bomb attack occurrence and lack of real data, the scenario of this research was not detailed enough. We plan to improve the scenario by considering the injury and contamination degree of the victims at different locations from the explosion point and apply virtual reality technology to the simulation of nuclear or radiological $\mathrm{MCl}$ for providing the response strategies on-site dynamically.

\section{Abbreviations}

RDD: Radiological dispersal device; MCI: Mass casualty incident; PPE: Personal protection equipment

\section{Declarations}

\section{Acknowledgements}

We thank Engineer Ma of Shenzhoupuhui Technology Co., Ltd. for his help in the construction of the simulation system.

Authors' contributions TY and YY wrote the article, and MY provided the idea. All authors have read and approved the final manuscript.

Funding Not applicable

Availability of data and materials Not applicable

Ethics approval and consent to participate Not applicable

Consent for publication Not applicable 
Competing interests The authors declare that they have no competing interests.

\section{References}

1. Aylwin CJ, König TC, Brennan NW, et al. Reduction in critical mortality in urban mass casualty incidents: analysis of triage, surge, and resource use after the London bombings on July 7, 2005[J]. Lancet. 2006, 368(9554):2219-2225.

2. Ryan J, Montgomery H. Terrorism and the Medical Response[J]. N Engl J Med. 2005, 353:543-545.

3. Tang Z, Li Y, Hu X, Wu H. Risk Analysis of Urban Dirty Bomb Attacking Based on Bayesian Network[J]. Sustainability. 2019, 11(2):306.

4. Lambert JH, Parlak Al, Zhou Q, et al. Understanding and managing disaster evacuation on a transportation network[J]. Accident Analysis \& Prevention. 2013, 50:645-658.

5. Rump A, Becker B, Eder S, Lamkowski A, Abend M, Port M. Medical management of victims contaminated with radionuclides after a "dirty bomb" attack[J]. Mil Med Res 2018, 5(1):27.

6. Reynolds SL, Crulcich MM, Sullivan G, Stewart MT. Developing a practical algorithm for a pediatric emergency department's response to radiological dispersal device events[J]. Pediatr Emerg Care 2013, 29(7):814-821.

7. Rogers MB, Amlôt R, Rubin GJ. The Impact of Communication Materials on Public Responses to a Radiological Dispersal Device (RDD) Attack[J]. Biosecur Bioterror 2013, 11(1):49-58.

8. Arguello I, Buis EJ. The global impacts of a terrorist nuclear attack: What would happen? What should we do?[J]. Bulletin of the Atomic Scientists 2018, 74(2):114-119.

9. Barnett DJ, Balicer RD, Blodgett D, Fews AL, Parker CL, Links JM. The application of the Haddon matrix to public health readiness and response planning[J]. Environ Health Perspect 2005, 113(5):561-566.

10. Gale RP. Medical and policy considerations for nuclear and radiation accidents, incidents and terrorism [J]. Curr Opin Hematol 2017, 24(6):496-501.

11. Hauer JM. US cities are not medically prepared for a nuclear detonation[J]. Bulletin of the Atomic Scientists 2017, 73(4):215-219.

12. Wolbarst AB, Wiley AL, Nemhauser JB, Christensen DM, Hendee WR. Medical Response to a Major Radiologic Emergency: A Primer for Medical and Public Health Practitioners[J]. Radiology. 2010, 254(3):660-677.

13. Becker SM, Middleton SA. Improving hospital preparedness for radiological terrorism: perspectives from emergency department physicians and nurses [J]. Disaster Med Public Health Prep 2008, 2(3):174-184.

14. Bushberg JT, Kroger LA, Hartman MB, et al. Nuclear/radiological terrorism: emergency department management of radiation casualties[J]. J Emerg Med 2007, 32(1):71-85.

15. Kobayashi L, Suner S, Shapiro MJ, et al. Multipatient disaster scenario design using mixed modality medical simulation for the evaluation of civilian prehospital medical response: a "dirty bomb" case 
study[J]. Simul Healthc 2006, 1(2):72-78.

16. Elcock D, Klemic GA, Taboas AL. Establishing remediation levels in response to a radiological dispersal event (or "dirty bomb")[J]. Environ Sci Technol 2004, 38(9):2505-2512.

17. Schleipman AR, Gerbaudo VH, Castronovo FP. Radiation Disaster Response: Preparation and Simulation Experience at an Academic Medical Center[J]. J Nucl Med Technol 2004, 32(1):22-27.

18. Rauner MS, Schaffhauser-Linzatti MM, Niessner H. Resource planning for ambulance services in mass casualty incidents: a DES-based policy model[J]. Health Care Management Science. 2012, 15(3):254-269.

19. Peng J, Xiang $\mathrm{H}$. Trauma undertriage and overtriage rates: are we using the wrong formulas?[J]. Am J Emerg Med. 2016, 34(11):2191-2192.

20. Frykberg ER, Tepas JJ. Terrorist bombings. Lessons learned from Belfast to Beirut[J]. Annals of Surgery. 1988, 208(5):569-576.

21. Lochey DJ, MacKenzie R, Redhead J, et al. London bombings July 2005: The immediate pre-hospital medical response[J]. Resuscitation. 2005, 66(2):ix-xii.

22. Barnes R, Hamwee S, McCartney J, Cross PH, Johnson D. Report of the 7 July review committee[EB/OL][J]. https://wwwlondongovuk/about-us/london-assembly/london-assemblypublications/report-7-july-review-committee. 2006:2006-06-01/2020-04-03.

\section{Figures}




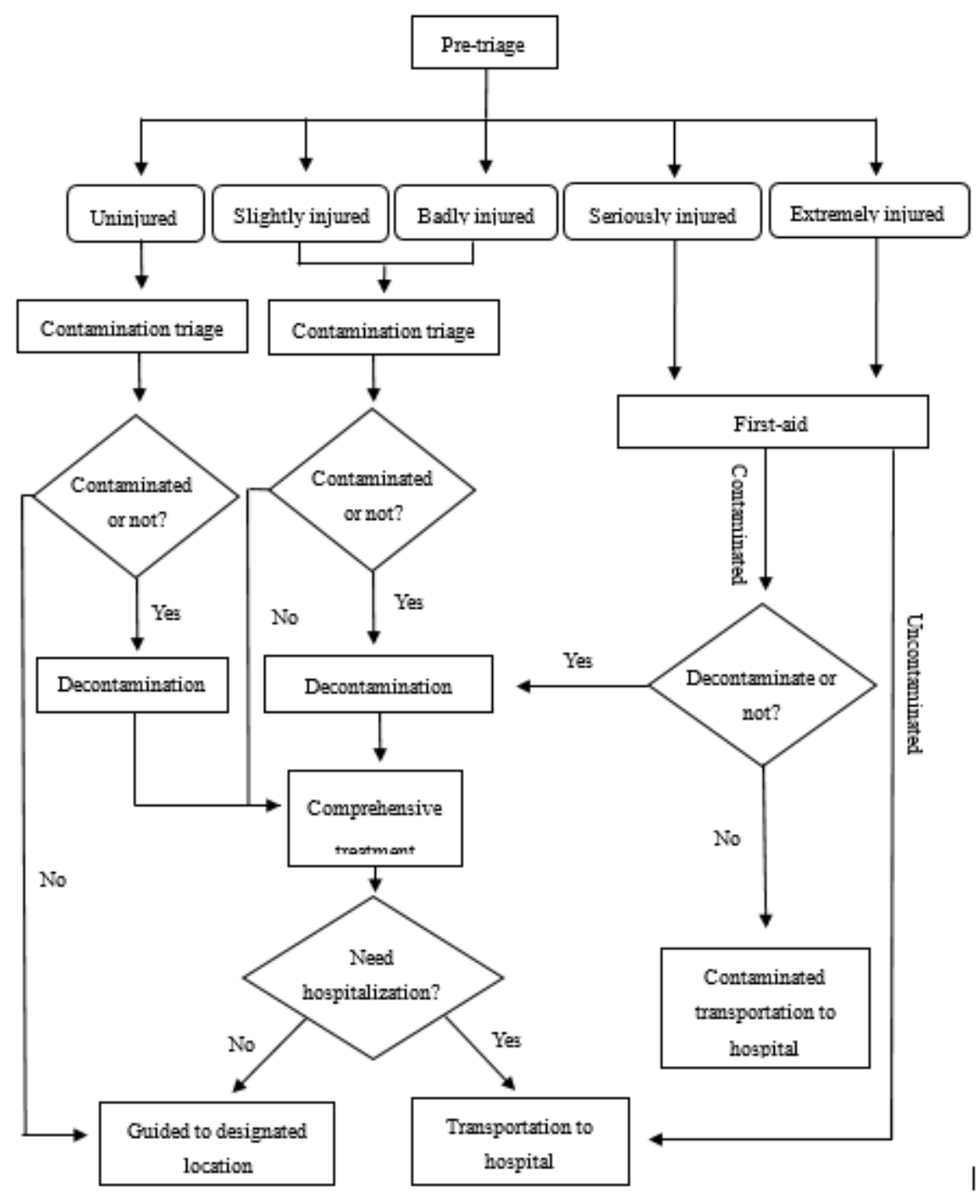

Figure 1

Nuclear or Radiological Emergency Medical Rescue Process 